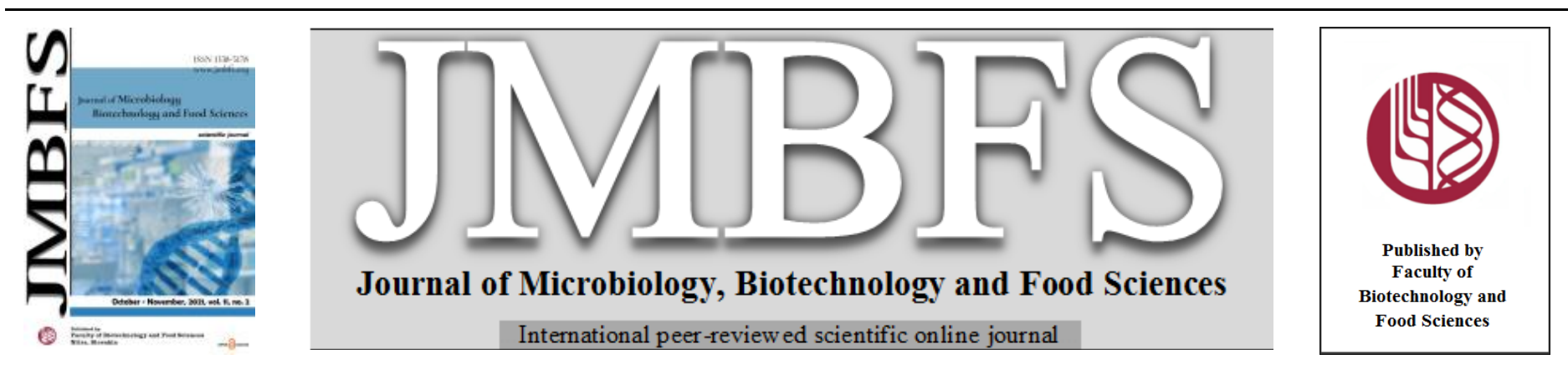

\title{
BIOCONVERSION OF WINE POMACE BY LENTINUS EDODES IN A SOLID-STATE SYSTEM
}

\author{
Hatice Kalkan Yıldırım*1, Eser Y. Sözmen ${ }^{2}$ \\ Address(es): \\ ${ }^{1}$ Ege University, Engineering Faculty, Department of Food Engineering, 35100 Bornova, Izmir, Turkey. \\ ${ }^{2}$ Ege University, Medical Faculty, Department of Biochemistry, 35100 Bornova, Izmir, Turkey.
}

*Corresponding author: hatice.kalkan.yildirim@ege.edu.tr

https://doi.org/10.15414/jmbfs.3006

ARTICLE INFO

Received 9. 4. 2020

Revised 30. 3. 2021

Accepted 13. 4. 2021

Published 1. 10. 2021

Regular article OPEN $\partial_{\text {ACCESS }}$

\begin{abstract}
Wine pomace is a by-product of wine industry. The objective of this investigation was to evaluate the biotransformation of wine pomace by $L$. edodes MCC 55. As substrates were used wine pomaces of Özbek and Gaziantep wines produced under conventional conditions. L.edobes MCC 55 cultures were used for biotransformation. During study were determined the effects of different media used during solid state fermentation (water and $\mathrm{CaCO}_{3}, \mathrm{NH}_{4} \mathrm{NO}_{3}$ ) and different solvents used during extraction (water and ethanol) on phenols and consequently their radical scavenging activities.

The ethyl alcohol used during extraction stages was determined as more effective solvent regarding antioxidant activity (TEAC) values. Using of water both during fermentation and extraction steps was determined to be significant for increasing the values of hydroxycinnamic and hydroxybenzoic acids. There were determined close relations among total phenol, tartaric acid esters, flavonols, anthocyanins and gallic acid values with samples produced by solid state fermentation with additional nutrient and using ethyl alcohol during extraction stage. Close interaction between antioxidant activity (TEAC) values and samples obtained by using ethanol during extraction were indicated, also. These results demonstrated that by-products such as wine pomace could be successfully used for production of valuable bioactive compounds.
\end{abstract}

Keywords: wine pomace, solid state fermentation, L.edobes, phenolic compounds

\section{INTRODUCTION}

In industry, raw materials are processed according to a certain purpose, while some substances emerging as waste material. Millions of waste materials are thrown into the environment almost every year. Wine pomace is the by-product of wine processing industry and consists chiefly of the skin, pulp and seed of the fruit. It is rich in dietary fiber, valuable bio products. Traditionally grape pomace is used as an ingredient in animal feed, but has little nutritional value as animal feed due to its low protein and carbohydrate content. In food industry, the use of by-products is important due to the high quantities of by-products and the additional cost of disposal (Larrauri et al, 1996). For example, $60 \%$ of cerea products, $85 \%$ of oilseed products, $90 \%$ of sugar products occurred as a waste material (Kahyaoğlu \& Konar, 2006). Grapes (Vitis vinifera L. subsp. vinifera) is associated with phenolic acids, flavonoids, stilbenes, anthocyanins and tannins, which are among antioxidant-containing fruits (Manconi et al., 2017). Wine pomace produced during wine making is a waste composed of grape seed, grape stalk and grape skin. The energy and nutrient requirements during biotransformation of waste materials is advantageous. Nowadays biotechnological methods are used more often to produce high quality bioactive compounds from food by-products (Schieber et al., 2001; Martinez-Avila et al, 2011).

Phenolic compounds found in wine and its by-products are divided into two groups: flavonoids and non - flavonoids. Phenolic compounds, which contain hydroxyl group (- $\mathrm{OH})$ attached to a benzene ring form part of the grape, such as the rind, core and stalk.

The flavonoids are present in the C6-C3-C6 diphenylpropane structure and the triple carbon bridge between the phenyl groups forms a ring with oxygen (Yıldırım et al., 2005; Annunziata, et al., 2019). The differences between different flavonoids arise from the number of attached hydroxyl groups, the degree of unsaturation and the degree of oxidation of the triple carbon segment. Researches are focused on the composition and health benefits of pomace due to main issues as: 1- Antioxidant effect of red wine pomaces; 2- Potential benefits for human health due to antimicrobial properties of red wine pomaces; 3 - Healthy fatty acids content in pomace. Among the main questions are how these pomace benefits could be incorporate into human practice. One of the most economical ways is to use biotechnological methods for extraction and bioconversion of these bioactive compounds.

Fungi contain extracellular enzymatic systems causing degradation of various wastes (Sánchez, 2009). In previous studies the valorization of wastes by solid culture fermentation using different fungi and substrates has been demonstrated. Evaluation of apple seed and cotton seed powder by Aspergillus niger for production of xylanase (Lee et al., 2008 Liu et al. 2008 ). Production of $\alpha$ amilase from rice by Aspergillus oryzae (Bhanja et al., 2008). Production of $\beta$ glycosidase from flour supplemented with guava waste by Rhizopus oligosporus (Correia et al., 2004). Evaluation of pomace obtained from cranberry by Lentinus edodes for production of $\beta$-glycosidase (Zheng \& Shetty, 2000a). Bioconversion of corn cobs substrates by Sporotrichum thermophile for production of xylanase (Topakas et al., 2003). Laccase production from wheat bran and wheat straw by Pleurotus pulmonarius (Laccase) (Marques et al., 2002) and by Pleurotus ostreatus (Baldrian \& Gabriel, 2002). Wine pomaces are waste composed of grape seed, grape stalk and grape skin, produced during wine making. According to data of FAO grapes take place in 61 million tons/year of production. During wine making approximately $17-20 \%$ of grapes are separated as pomace which causes emerging of 12 million tons annually in the world. The wine pomace is rich in antioxidants (Kalli et al., 2018). It is considered as 20 times more powerful antioxidant than vitamin $\mathrm{E}$ and 50 times than $\mathrm{C}$ vitamin.

The objective of this study was to investigate the bioconversion of wine pomace by $L$. edodes MCC 55 by solid state fermentation. Pomace obtained during production of wines of two different grape variety (Gaziantep and Özbek) were subjected to solid state fermentation by $L$. edodas in presence of different compounds $\left(\mathrm{CaCO}_{3}, \mathrm{NH}_{4} \mathrm{NO}_{3}\right)$. After fermentation, extractions were carried out by using different solvents (water, ethanol). The effects of all these parameters on inhibition of LDL oxidation, antioxidant activity, total phenolic contents, tartaric acid esters, total flavonols, total anthocyanins and some individual phenolic compounds were determined. 


\section{MATERIAL AND METHODS}

\section{Material}

The wine pomaces were obtained from wine production by using Gaziantep and Özbek grapes processed in Ege University Engineering Faculty, Food Engineering Department. Grape pomaces were subjected to dring for $24 \mathrm{~h} / 60^{\circ} \mathrm{C}$ and milling to a fine powder form with size less than $1 \mathrm{~mm}$ and kept in refrigerator before use.

\section{Microorganism}

Lentinus edodes MCC 55 was obtained from the Collection of Fatih Kalyoncu, Biology Department - Celal Bayar University in Manisa. Lentinus edodes MCC 55 was propagated and preserved on PDA at $4{ }^{\circ} \mathrm{C}$. The fungus was activated by transferring onto PDA plate and cultured for 20 days $/ 28^{\circ} \mathrm{C}$ before use.

\section{Culture media and solid state fermentation}

The production process was schematically shown in figure 1. Evaluated parameters and sample numbers are demonstrated in Table 1. Each grape pomace (Gaziantep and Özbek) were enriched with different media $\left(0.5 \mathrm{~g} \mathrm{CaCO}_{3} ; 0.5 \mathrm{~g}\right.$ $\mathrm{NH}_{4} \mathrm{NO}_{3} ; 20 \mathrm{ml}$ water). The media (125ml flasks) was sterilized at $121^{\circ} \mathrm{C} / 15 \mathrm{~min}$ conditions. Lentinus edodes MCC 55 (3\%) mycelium prepared in PDA plate was inoculated into flasks and incubated at $28^{\circ} \mathrm{C} / 20$ days.
Process 1

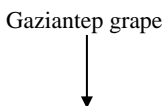

Alcohol fermentation

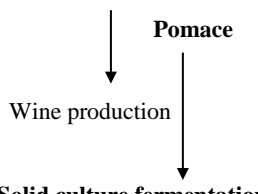

Solid culture fermentation (Lentinus edodes MCC55)

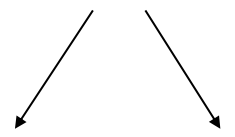

+ Pure water
$+\mathrm{CaCO}_{3}$

$+\mathrm{NH}_{4} \mathrm{NO}_{3}$

+ Pure water
Process 2

Uzbek grape

Alcohol fermentation

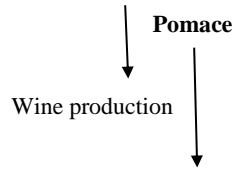

Solid culture fermentation

(Lentinus edobes MCC55)

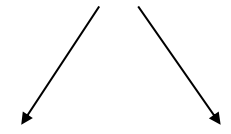

+ Pure water

$+\mathrm{CaCO}_{3}$

$+\mathrm{NH}_{4} \mathrm{NO}_{3}$

+ Pure water
Extraction procedures

Fermented product 1 Fermented product 2

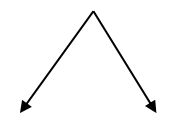

Water Ethano

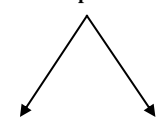

Water Ethanol
Extraction procedures
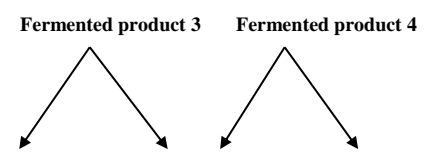

Water
Ethanol Water

Ethanol
1$$
2
$$$$
3
$$$$
4
$$

Table 1 Samples and process parameters

\begin{tabular}{|c|c|}
\hline $\begin{array}{l}\text { Sample } \\
\text { No }\end{array}$ & Process parameters \\
\hline S1 & $\begin{array}{l}\text { Gaziantep pomace/water addition in solid culture } \\
\text { fermentation/extraction with water }\end{array}$ \\
\hline $\mathrm{S} 2$ & $\begin{array}{l}\text { Gaziantep pomace/water addition in solid culture } \\
\text { fermentation/extraction with ethanol }\end{array}$ \\
\hline S3 & $\begin{array}{l}\text { Gaziantep pomace/water and nutrient addition in solid culture } \\
\text { fermentation/extraction with water }\end{array}$ \\
\hline $\mathrm{S} 4$ & $\begin{array}{l}\text { Gaziantep pomace/water and nutrient addition in solid culture } \\
\text { fermentation/extraction with ethanol }\end{array}$ \\
\hline S5 & $\begin{array}{l}\text { Özbek pomace/water addition in solid culture } \\
\text { fermentation/extraction with water }\end{array}$ \\
\hline S6 & $\begin{array}{l}\text { Özbek pomace/water addition in solid culture } \\
\text { fermentation/extraction with ethanol }\end{array}$ \\
\hline S7 & $\begin{array}{c}\text { Özbek pomace/water and nutrient addition in solid culture } \\
\text { fermentation/extraction with water }\end{array}$ \\
\hline S8 & $\begin{array}{l}\text { Özbek pomace/water and nutrient addition in solid culture } \\
\text { fermentation/extraction with ethanol }\end{array}$ \\
\hline
\end{tabular}

\section{METHODS OF ANALYSIS}

\section{Inhibition of low density lipoprotein (LDL) oxidation}

The Inhibition of \%LDL oxidation was performed, as described before (Yıldırım et al., 2005). Plasma samples were subjected to stand for $30 \mathrm{~min} /$ room temperature with LDL particles and samples were centrifuged (1600 x $10 \mathrm{~min})$. Then $0.015 \mathrm{~N} \mathrm{NaOH}$ was added to the samples. Inhibition of \%LDL oxidation was evaluated at $234 \mathrm{~nm}$ by spectrophotometer and the calculations were performed using the extinction coefficient of $29.5001 \mathrm{~mol}_{-} \mathrm{cm}^{-1}$

\section{Antioxidant activity (TEAC)}

The antioxidant activity was determined by using ABTS radical decolourisation modified assay ( $\operatorname{Re} \boldsymbol{e t}$ al., 1999). ABTS, 2,2'-azinobis (3-ethylbenzothiazoline-6sulfonic acid) was dissolved using water to a $7 \mu \mathrm{M}$ concentration. The ABTS cation $\left(\mathrm{ABTS}^{*+}\right.$ ) was produced by mixing ABTS stock solution with $2.45 \mu \mathrm{M}$ potassium persulfate (final concentration) and stored in the dark / room temperature for $12 \mathrm{~h}$ before use. The samples containing the ABTS ${ }^{+}$solution were diluted with phosphate buffer solution $\left(1 / 25: \mathrm{v} \mathrm{v}^{-1}\right)$ to an absorbance of 1.0 1.5 at $734 \mathrm{~nm}$. After addition of $975 \mu \mathrm{l}$ of diluted ABTS $^{-+}$solution to $5-25 \mu \mathrm{l}$ of polyphenolic extracts absorbance values were read. Trolox was used as a standard. The results were expressed as Trolox equivalents (Teleszko \& Wojdyło, 2015).

\section{Antioxidant activity (Total Sulfhydryl Group)}

The total sulfhydryl group analysis was determined as described before (Habeeb, 1972). DTNB 5,5'-dithiobis (2-nitrobenzoic acid) was added sodium phosphate buffer $(\mathrm{pH}=8.0$ ) to a $0.08 \mathrm{M}$. After addition of solution to polyphenolic extracts absorbance values were read. As a standard was used glutathione.

\section{Total phenolic content}

Total phenolic content was determined by the Folin-Ciocalteu method (Singleton \& Rossi, 1965) by carrying out the following modification to reduce the assay volume. To $3.90 \mathrm{ml} \mathrm{H}_{2} \mathrm{O}$ was added $0.1 \mathrm{ml}$ sample followed by $0.5 \mathrm{ml}(25 \mathrm{ml}$ Folin Ciocalteu reagent in $75 \mathrm{ml} \mathrm{H}_{2} \mathrm{O}$ ) Folin-Ciocalteu reagent (Merck, Darmstadt, Germany) mix. After 3-6 min, $0.5 \mathrm{ml}$ saturated sodium carbonate (20 $\mathrm{g} \mathrm{Na}_{2} \mathrm{CO}_{3}$ in $100 \mathrm{ml} \mathrm{H}_{2} \mathrm{O}$ ) (Merck) was added. After vigorous mixing with a vortex and waiting for $30 \mathrm{~min}$, the reading was performed at $725 \mathrm{~nm}$ (Pharmacia LKB Novaspec $\uparrow$ II spectrophotometer, Uppsala, Sweden). The calibration figure was obtained by using following quantities of gallic acid stock solution: 0-1-2-3 $5-10-12-17$ and $20 \mathrm{ml}$ in $100 \mathrm{ml}$ which is corresponding to $0-50-100-150-250$ 500-600-850 and $1000 \mathrm{mg} \mathrm{L}^{-1}$ gallic acid. The results were expressed as gallic acid equivalents (GAE) using a calibration curve against a gallic acid (Merck) Standard (100 $\left.\mathrm{mg} \mathrm{L}^{-1}\right)$ (Yıldırım et al., 2015).

\section{Tartaric ester content}

The amounts of tartaric ester were determined as caffeic acid equivalents using the modified version of the Glorie's method (Gil-Muñoz et al., 1999). Diluted samples $(1 \mathrm{ml})$ were mixed with ethanol $(9 \mathrm{ml})$. The obtained solution was additionally mixed with $0.25 \mathrm{ml}$ of $1 \% \mathrm{HCl}$ and $4.55 \mathrm{ml}$ of $2 \% \mathrm{HCl}$. After vigorous mixing with a vortex and waiting for $15 \mathrm{~min}$, the reading was performed at $320 \mathrm{~nm}$ (Pharmacia LKB Novaspec $\dagger$ II spectrophotometer, Uppsala, Sweden). The calibration curve was obtained by using following quantities of caffeic acid stock solution: 0-1-2-3-4 in 100ml. The results were expressed as caffeic acid equivalents (CAE) using a calibration curve against a caffeic acid (Merck) Standard (100 $\mathrm{mg} \mathrm{L}^{-1}$ ) (Ylldırım et al., 2015). 


\section{Total flavonol content}

The amounts of tartaric ester were determined as quercetin equivalents using the modified version of the Glorie's method (Gil-Muñoz et al., 1999). Diluted samples $(1 \mathrm{ml})$ were mixed with ethanol $(9 \mathrm{ml})$. The obtained solution was additionally mixed with $0.25 \mathrm{ml}$ of $1 \% \mathrm{HCl}$ and $4.55 \mathrm{ml}$ of $2 \% \mathrm{HCl}$. After vigorous mixing with a vortex and waiting for $15 \mathrm{~min}$, the reading was performed at $360 \mathrm{~nm}$ (Pharmacia LKB Novaspec $\dagger$ II spectrophotometer, Uppsala, Sweden). The calibration curve was obtained by using following quantities of quercetin stock solution: $0-0.25-0.5-0.75-1-1.25-1.5$ and $2 \mathrm{ml}$ in $100 \mathrm{ml}$. The results were expressed as quercetin equivalents (CAE) using a calibration curve against a quercetin (Merck) Standard (100 $\left.\mathrm{mg} \mathrm{L}^{-1}\right)$ (Yıldırım et al., 2015).

\section{Total anthocyanin (malvidin-3-diglucoside) content}

The monomeric anthocyanin was determined by spectrophotometric method, as described by AOAC Official Method (Mertens, 2005). The principle of this method is that the anthocyanins can form reversed colored and colorless forms at different $\mathrm{pH}$ values ( $\mathrm{pH}$ : 1 colored form and $\mathrm{pH}$ : 4.5 colorless forms) and differences from these values in absorbance measurements for spectrophotometrically at $520 \mathrm{~nm}$. The total monomeric anthocyanins content was expressed as malvidin-3-glucoside equivalents.

\section{High-performance liquid chromatography analysis (HPLC)}

Phenolic acids used as standards were obtained from Sigma Chemical Company Frankfurt/Germany). Solvents used were supplied by J.T. Baker (New Jersey/USA) and Riedel-de Haen AG (Darmstadt/Germany). Membranes (0.45 $\mu \mathrm{m}$ pore size) used for filtration of the samples were obtained from Sartorius AG (Darmstadt/Germany) (16555 Minisart). The analyses were performed on an Agilent 1200 series HPLC (Agilent Technologies, Santa Clara, CA, USA) equipped with HPLC-UV-DAD detector. Separation was achieved on C-18 column of $25 \mathrm{~cm} \times 4.6 \mathrm{~mm}$. $20 \mu \mathrm{l}$ of filtered sample was injected to the system, column oven was set to $35^{\circ} \mathrm{C}$, a flow rate of $0.8 \mathrm{~mL} \mathrm{~min}^{-1}$ was used. As the solvent A was used $0.1 \%$ (v/v) phosphoric acid, and as solvent B was used acetonitrile. Both solvents were degassed (ELMA LC 30/H ultrasonic bath/Darmstadt/Germany) for $15 \mathrm{~min}$ before using. Standards were prepared as $500 \mathrm{ppm}$ and calibration curves were evaluated. Quantitative determinations were carried out by the external standard method based on peak areas. Samples were filtered through a $0.45 \mu \mathrm{m}$ (Sartorius PTFE syringe filter) membrane. Each compound was tentatively identified by retention time under the same conditions (Kilinc \& Kalkan, 2003)

\section{Statistical analyses}

Significant differences between means were determined at a $95 \%$ significance level. Using a Post-Hoc test, least significant difference (LSD) tests were performed. Multivariate data analysis techniques were performed to analyze all data by using standardized values of parameters. Principal component analysis permits the visualization of the original arrangement of wines in an ndimensional space, by identifying the directions in which most of the information is retained.

\section{RESULTS AND DISCUSSION}

The conversion of food wastes into various value-added products through solidstate fermentation has been of major interest to many laboratories all over the world. This type of fermentation is carried out by using water-insoluble materials such as pomace for microbial metabolism compared with submerged fermentation. Pomace of grapes contains low amount of protein and high amount of tartaric acids that's way it has limited use as animal feed. Its usage as fertilizer is not economically competitive and caused some environmental problems. Since grape pomace contains large amount of valuable bioactive compounds some ways of utilization have been developed. Among them are some physical and chemical extraction methods (Yıldırım et al., 2005; Pintác et al., 2018, Kalli et al., 2018). Except these procedures the best promising way of usage are by biotechnological techniques allowing separation of free and bound compounds. So, in this study the bioconversion of wine pomace by L. edodes in a solid state system with different medium and different exaction solvents has been evaluated.

\section{Evaluation of inhibition of LDL oxidation}

It is well known that the antioxidant properties of phenolic compounds found in red wine could lead to inhibition of low density lipoproteins oxidation (Franke et al., 1995; Abu-Amsha et al., 1996; Teissedre et al., 1996). Frankel et al., had demonstrated also that alcohol-free components obtained from the wine inhibited LDL oxidation more prominently than alpha-tocopherol (Frankel $\boldsymbol{e t}$ al., 1993). In our study, it was demonstrated that some compounds found in wine pomace of Gaziantep and Özbek grapes subjected to biotransformation by L. edodes MCC 55 inhibit LDL oxidation. The LDL oxidation inhibition value was found to be
$55.95 \%$ for S2 sample and $48.80 \%$ for S6 sample. The highest LDL oxidation inhibition value was determined as $63.87 \%$ for S3 sample. The results demonstrated that inhibition of LDL oxidation is affected from grape varieties, addition of nutrients prior solid state fermentation and solvent type used during extraction. Better results were determined with Gaziantep grape variety, enriched medium and exaction with ethanol. Even the highest value was detected with water solvent all other results lead to higher percentage of inhibition of LDL oxidation by ethanol extraction (44\%) than with water $(25 \%)$. In our previous studies we determined that grape varieties have a crucial role in inhibition of LDL oxidation in wines (Yıldırım et al., 2004; Yıldırım et al., 2005; Sezer et al., 2007; Öztürk et al., 2016). This is supported by other authors also (Martins et al., 2016; Annuziata et al., 2019). This is closely related with phenolic content and type of phenols present in grapes and respectively with their pomaces. It was emphasized that wine pomace medium supplemented with $\mathrm{CaCO}_{3}$ and $\mathrm{NH}_{4} \mathrm{NO}_{3}$ allowed better growth of selected fungi, better biotransformation of phenols present in wine pomace and indirectly higher percentage of LDL oxidation inhibition. The effect of added nutrient to fruit waste and their effects over L.edobes was demonstrated in other studies, also (Zheng \& Shetty, 1998; Vattem \& Shetty, 2003). 2).

\section{Evaluation of antioxidant activity}

Researches demonstrated that some phenolic compounds possess excellent antioxidant properties. (Correia et al., 2004; Keser et al., 2012; Öztürk et al., 2016; Pintác et al., 2018). Phenolic compounds are known to have radical scavenging (antioxidant) activity that depends on their reactivity as hydrogen or electron donors, the stability of the radicals, and their relationship to other metal chelate properties (Zheng \& Shetty, 2000,b; Correia et al., 2004; Randhir \& Shetty, 2007). Most of these compounds are found in grapes and respectively in wine and wine pomaces (Keser et al., 2012; Öztürk et al., 2016). The type and quantities of phenols present in pomace determine the power of antioxidant activities after biotransformation. Considering the antioxidant activity (TEAC) of samples obtained at different conditions (solid state fermentation, extraction process) there were determined significant differences $(\mathrm{p}<0.05)$ among samples regarding the medium (without nutrient/nutrient addition) used in the solid state fermentation stage and the solvents (water / ethanol) used in the extraction stage The highest antioxidant activity (TEAC) values $(0,48 \%)$ was obtained in samples of Gaziantep wine pomace with addition of $\mathrm{CaCO}_{3}$ and $\mathrm{NH}_{4} \mathrm{NO}_{3}$ to the medium considering fermentation stage and using of ethanol at extraction process. The $\mathrm{C} / \mathrm{N}$ ratio $(10 / 100)$ is an important indicator of nutritional regulation of fungi growth during solid state fermentation. Usually the presence of $\mathrm{C}$ and $\mathrm{N}$ is more important than the ideal ratio. In most studies of using pomace during such fermentation the carbon source coming from natural sources could be enough but the nitrogen source is usually insufficient (Vattem \& Shetty, 2002; Shah et al., 2005; Gaitán-Hermández et al., 2006). As was in case of LDL oxidation inhibition values, the antioxidant activity values was higher in samples with fermentation medium supplemented with $\mathrm{CaCO}_{3}$ and $\mathrm{NH}_{4} \mathrm{NO}_{3}$ allowing better growth of selected fungi, better biotransformation of phenols present in wine pomace. The positive correlations were determined between total phenols (gallic acid equivalent) and antioxidant activity (TEAC) $(\mathrm{r}=0.73, \mathrm{p}<0.038)$. As was in the case of LDL oxidation the higher percentage by antioxidant activity was detected by ethanol extraction $(0,40 \%)$ than with water $(0,32 \%)$. These results indicated that most phenols remaining in wine pomace of Gaziantep and Özbek acting as antioxidants are ethanol extractable ones. The solvent power of ethanol was determined by other authors, also (Zheng\& Shetty, 1998; Vattem \& Shetty, 2003; Pintác et al., 2018) The antioxidant activity value in case of the total sulfhydryl group was found to be $319.84 \mathrm{nmol} \mathrm{ml}^{-1}$ as the highest value in the S1 sample (Gaziantep wine pomace) with medium without any added nutrients during solid state fermentation and extraction done with water as the solvent. In case of addition of $\mathrm{CaCO}_{3}$ and $\mathrm{NH}_{4} \mathrm{NO}_{3}$ to the medium and extraction with ethanol the highest antioxidant activity value (total sulfhydryl) was obtained as $314.50 \mathrm{nmol} \mathrm{ml}^{-1}$ in the sample of S4 (Gaziantep wine pomace) and the lowest value as $283.20 \mathrm{nmol} \mathrm{ml}^{-1}$ in the sample of $\mathrm{S} 8$ (Özbek wine pomace). These differences were found to be statistically insignificant. Among the samples without nutrients, $316.79 \mathrm{nmol} \mathrm{ml}^{-1}$ value was found to be the highest in S6 sample extracted with ethanol using Özbek grape pomace. In case of addition of $\mathrm{CaCO}_{3}$ and $\mathrm{NH}_{4} \mathrm{NO}_{3}$ to the medium and extraction with ethanol the highest antioxidant activity value (total sulfhydryl) was obtained as $314.50 \mathrm{nmol} \mathrm{ml}^{-1}$ in the sample of S4 (Gaziantep wine pomace) and the lowest value as $283.20 \mathrm{nmol}$ $\mathrm{ml}^{-1}$ in the sample of S8 (Özbek wine pomace).

Evaluation of total phenolic contents, tartaric acid ester, total flavonol and total anthocyanin

Phenolic compounds found in grape pomace are mostly found in bound (insoluble) form and only relatively small amounts were in free phenolic acid form. (Yıldırım et al., 2015). That's way the analyses of phenols covered some main groups as total phenolic contents, tartaric acid esters, total flavonols and total anthocyanins and some individual phenolic compounds. 
The highest total phenol value (259 $\left.\mathrm{mg} \mathrm{l}^{-1}\right)$ was obtained in the sample S4 by using Gaziantep wine pomace with addition of nutrients $\left(\mathrm{CaCO}_{3}\right.$ and $\left.\mathrm{NH}_{4} \mathrm{NO}_{3}\right)$ and extraction with ethanol. In case of solid state fermentation without any nutrients and using of water during extraction the total phenol values drop to 175 $\mathrm{mg} \mathrm{l}^{-1}$ (S1 sample). In previous studies changes of total phenol values were determined in cranberry pomace using solid state fermentation by $L$. edodes (Vattem \& Shetty, 2003) and Rhizopus oligospous (Vattem \& Shetty, 2002). They demonstrated that at the end of fermentation, the extraction of phenolic compounds with ethanol lead to higher phenolic component content than treatment with water. Our results support these findings. Considering using of different solvents during extraction stage it has been found that there is a statistically significant difference between $(\mathrm{p}<0.05)$ total phenolic conten (gallic acid equivalent), tartaric acid ester (quercetin equivalent) and gallic acid content. Positive correlations were determined between total phenols ( gallic acid equivalent) and antioxidant activity (TEAC), $(\mathrm{r}=0,73, \mathrm{p}<0,038)$, tartaric acid esters (quercetin equivalent) $(r=0,98, p<0,020)$; total anthocyanins (malvidin-3 glycoside) $(r=0,86, p<0,006)$, total flavonol (caffeic acid) $(r=0,94, p<0,002)$ and gallic acid $(r=0,72, p<0,045)$.

Similar relations were obtained for the tartaric acid esters. With addition of $\mathrm{CaCO}_{3}$ and $\mathrm{NH}_{4} \mathrm{NO}_{3}$ to the medium during solid state fermentation and extraction with ethanol the highest tartaric acid esters value $\left(1.11 \mathrm{mmol}^{-1} \mathrm{~L}\right)$ was obtained by using Gaziantep wine pomace (S4).The effects of added nutrients and used grape origin were seen in the following values. In samples with medium without nutrients and extraction with ethanol the highest value for the tartaric ester was found to be $1.01 \mathrm{mmol} \mathrm{L}^{-1}$ in the sample S2 using Gaziantep wine pomace. Changing the grape origin (Özbek) and using medium without nutrition lead to drop of tartaric acid esters value to $0.75 \mathrm{mmol} \mathrm{L}^{-1}$ in the sample. Positive correlations were determined between tartaric acid (quersetin equivalent) and antosiyanin (malvidin-3 glycoside) $\mathrm{r}=0,92, \mathrm{p}<0,002)$, (caffeic acid) $(\mathrm{r}=0,97$, $\mathrm{p}<0,002)$ and gallic acid $(\mathrm{r}=0,80, \mathrm{p}<0,045)$

Wine pomace obtained of fruits Vitis spp. are known to be rich in flavonoids and their derivatives $(12,15,16)$. The highest total flavonol value $\left(0,49 \mathrm{mmol}^{-1} \mathrm{~L}\right)$ was found in the sample $\mathrm{S} 4$ by using Gaziantep wine pomace without addition of nutrients $\left(\mathrm{CaCO}_{3}\right.$ and $\left.\mathrm{NH}_{4} \mathrm{NO}_{3}\right)$ and extraction with ethanol. The highest total anthocyanins value was found to be $54.41 \mathrm{mmol} \mathrm{L}^{-1}$ as was in the case with flavonol content in the samples obtained with medium without nutrient and treated with ethanol as solvent in Gaziantep wine pomace. With the addition of $\mathrm{CaCO}_{3}$ and $\mathrm{NH}_{4} \mathrm{NO}_{3}$ to the medium and extraction with ethanol the total anthocyanins content was drop to $46.07 \mathrm{mmol} \mathrm{L}^{-1}$ and flavonol drop to 0.45 $\mathrm{mmol} \mathrm{L}^{-1}$. These results demonstrated that the accumulation of anthocyanin and flavonol content could be performed without any additional nutritional supply for medium during solid state fermentation. Positive correlations were determined between tartaric acid esters (quercetin equivalent) and anthocyanins (malvidin-3 glucoside) ( $\mathrm{r}=0.92, \mathrm{p}<0.002)$, flavonol (caffeic acid), $(\mathrm{r}=0.97, \mathrm{p}<0.002)$ and gallic acid $(\mathrm{r}=0.80, \mathrm{p}<0.045)$.

\section{Evaluation of phenolic compounds analyzed by HPLC}

Extraction and bioconversion of phenolic compounds from fruit pomace have been reported in many studies (Zheng \& Shetty, 2000 a; Vattem \& Shetty, 2002; Vattem \& Shetty, 2003). Zheng and Shetty investigated using of cranberry pomace as a substrate for production of free phenolics by L.edodes (Zheng \& Shetty, 2000a). The results demonstrated that L.edodes could be played an important role for production of phenolic compounds. Considering the importance of the phenolic groups found in grape, wine and respectively in wine pomace some phenolic compounds were identified and evaluated by highperformance liquid chromatography (HPLC).

One of the main representatives of phenolic acids in wine pomace is hydroxycinnamic acid. The highest value $(0,79 \mathrm{ppm})$ of its was obtained in the sample by using Gaziantep wine pomace with addition of nutrients $\left(\mathrm{CaCO}_{3}\right.$ and $\mathrm{NH}_{4} \mathrm{NO}_{3}$ ) during solid state fermentation and ethanol during extraction. Slightly low value was obtained with conditions without additional nutrients $(0,71 \mathrm{ppm})$. The other one important representative of phenolic acids in wine pomace is hydroxybenzoic acid. The highest values for hydroxybenzoic acid and gallic acid were obtained as was in case of hydroxycinnamic acid conditions. Similarly, Zheng \& Shetty, 2000 demonstrated that ellagic acid increases after solid state fermentation using cranberry pomace by L.edodes. Our results are in accordance with previous data obtained during bioconversion of phenols and their releases as aglicone forms (Zheng \& Shetty, 1998; Zheng \& Shetty, 2000a; Vattem \& Shetty, 2003; Gaitán-Hermández et al., 2006; Lee et al., 2008)

Principal component analysis (eigenvalue count), shown in figure 2, was performed on the dataset to investigate the interrelationship of the attributes and to show the differences among products and the analyzed parameters. The loading plots for the first two factors $(53.79 \%$ x $20.04 \%)$ were assumed to sum up the first two principal components with more than $73.00 \%$. Since the distribution of the analyzed parameters (figure 3), the samples prepared with different fermentation media (figure 4) and the different solvents (figure 5) have the same values as $53.79 \%$ x $20.04 \%$, these parameters were evaluated together fitting the values.

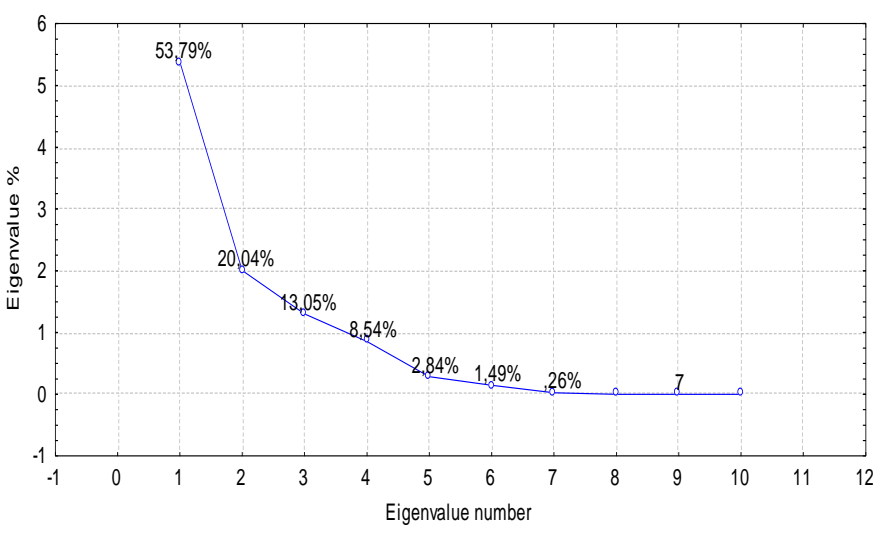

Figure 2 Eigenvalue number

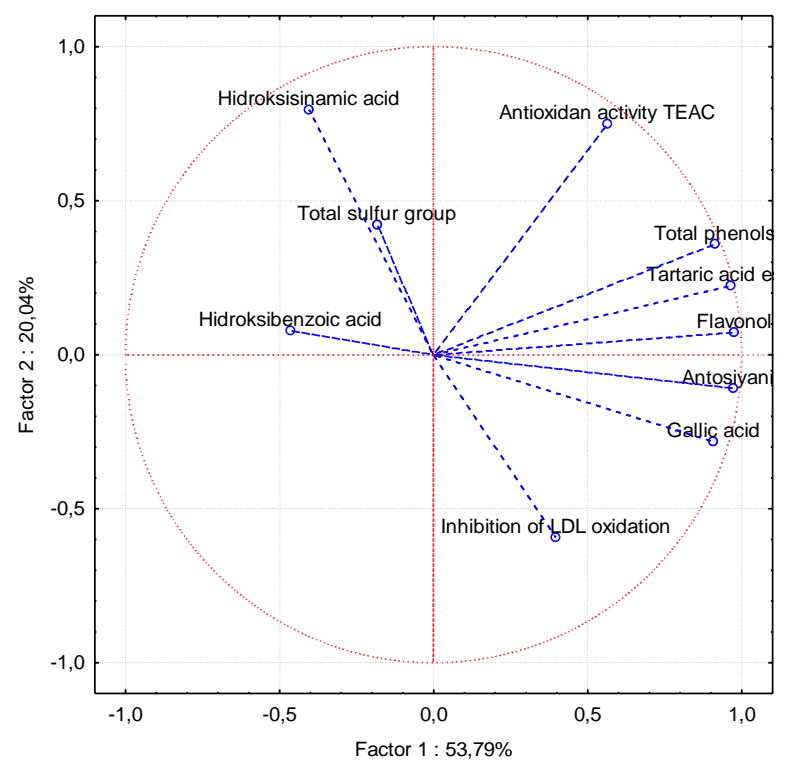

Figure 3 Distribution of analyzed parameters (solid culture fermentation / extraction processes)

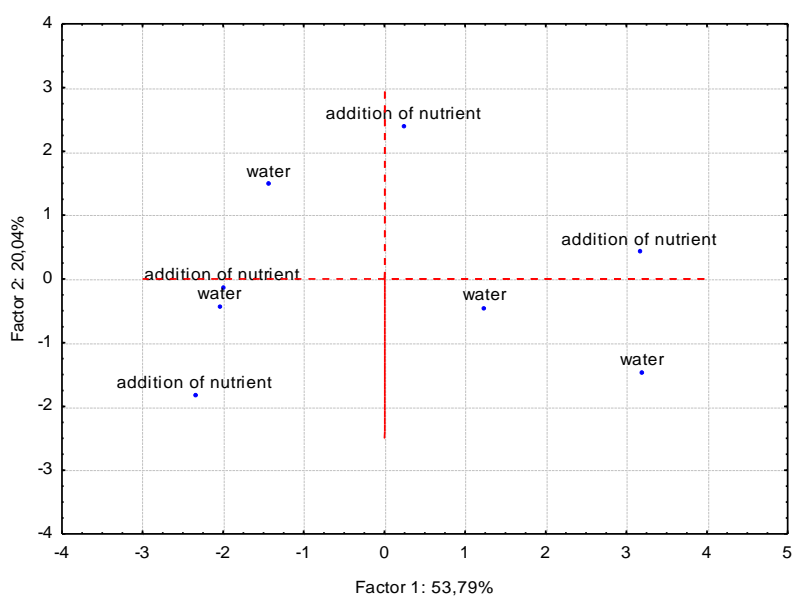

Figure 4 The effects of medium (pure water / added nutrients) on the parameters used in solid culture fermentation stage 


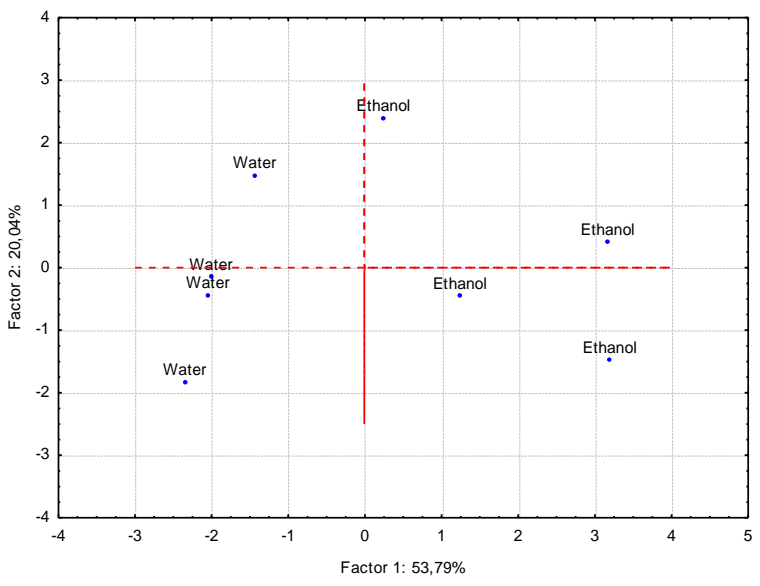

Figure 5 The effects of medium (pure water / ethyl alcohol) on the parameters used in the extraction stage

As a results of such analyses there were determined close relations among tota phenol, tartaric acid esters, flavonols, anthocyanins and gallic acid values with samples produced by solid state fermentation with additional nutrient and using ethyl alcohol during extraction stage. Similar results were obtained for hydroxycinnamic and hydroxybenzoic acids, also. Close relation between antioxidant activity (TEAC) values and samples obtained by using ethanol during extraction were indicated.

\section{CONCLUSION}

The present work demonstrated feasibilities of wine pomace biotransformation by solid state fermentation using $L$. edodes MCC 55 with different nutrien medium and different extraction solutions. Wine pomace of Gaziantep and Özbek grapes subjected to biotransformation by L. edodes MCC 55 caused inhibition of LDL oxidation. The percentage of inhibition is affected by used grape varieties, addition of nutrients prior solid state fermentation and solvent type used during extraction. Better results were determined with Gaziantep grape variety, enriched medium and exaction done with ethanol.

Wine pomace medium supplemented with $\mathrm{CaCO}_{3}$ and $\mathrm{NH}_{4} \mathrm{NO}_{3}$ allowed better growth of selected fungi, better biotransformation of phenols present in wine pomace causing higher antioxidant activity (TEAC) and indirectly inhibition of LDL oxidation. The accumulation of anthocyanin is less affected by additional nutritional supply of medium during solid state fermentation.

The results of multivariate analyses demonstrated close relations among tota phenol, tartaric acid esters, flavonols, anthocyanins and gallic acid values with samples produced by solid state fermentation with additional nutrient and using ethyl alcohol during extraction stage. Similar results were obtained for hydroxycinnamic and hydroxybenzoic acids, also. Marked relation was determined between antioxidant activity (TEAC) values and samples obtained by ethanol extraction.

These results revealed that by-products such as wine pomace could be successfully used for production of valuable bioactive compounds by solid-state fermentation considering extraction solvents, used culture and biotransformation conditions.

Acknowledgments: This research was supported by the Ege University Scientific Research Projects Coordination Unit. Project Number 11-Müh / 071.

Conflict of Interest: The authors have no conflict of interest to declare.

\section{REFERENCES}

Abu-Amsha, R., Croft, K. D., Puddey, I. B., Proudfoot, J. M., \& Beilin, L. J. (1996). Phenolic Content of Various Beverages Determines the Extent of Inhibition of Human Serum and Low-Density Lipoprotein Oxidation in Vitro: Identification and Mechanism of Action of Some Cinnamic Acid Derivatives from Red Wine. Clinical Science, 91(4), 449-458. https://doi:10.1042/cs0910449 Annunziata, G., Maisto, M., Schisano, C., Ciampaglia, R., Narciso, V., Hassan, S. T. S., Novellino, E. (2019). Effect of Grape Pomace Polyphenols With or Without Pectin on TMAO Serum Levels Assessed by LC/MS-Based Assay: A Preliminary Clinical Study on Overweight/Obese Subjects. Frontiers in Pharmacology, 10. https://doi:10.3389/fphar.2019.00575

Baldrian, P., \& Gabriel, J. (2002). Variability of laccase activity in the white-rot basidiomycetePleurotus ostreatus. Folia Microbiologica, 47(4), 385-390. https://doi:10.1007/bf02818695

Bhanja, T., Rout, S., Banerjee, R., \& Bhattacharyya, B. C. (2008). Studies on the performance of a new bioreactor for improving antioxidant potential of rice. LWT - Food Science and Technology, 41(8), 1459-1465 https://doi:10.1016/j.lwt.2007.08.015
Correia, R. T. P., Mccue, P., Magalhães, M. M. A., Macêdo, G. R., \& Shetty, K (2004). Phenolic Antioxidant Enrichment Of Soy Flour-Supplemented Guava Waste By Rhizopus Oligosporus-Mediated Solid-State Bioprocessing. Journal Of Food Biochemistry, 28(5), 404-418. https://doi:10.1111/J.1745 4514.2004.05703.x

Frankel, E. ., German, J. ., Kinsella, J. ., Parks, E., \& Kanner, J. (1993) Inhibition of oxidation of human low-density lipoprotein by phenolic substances in red wine. The Lancet, 341(8843), 454-457. https://doi:10.1016/01406736(93)90206-v

Frankel, E. N., Waterhouse, A. L., \& Teissedre, P. L. (1995). Principal Phenolic Phytochemicals in Selected California Wines and Their Antioxidant Activity in Inhibiting Oxidation of Human Low-Density Lipoproteins. Journal of Agricultural and Food Chemistry, 43(4), 890-894. https://doi:10.1021/jf00052a008

Gaitán-Hernández, R., Esqueda, M., Gutiérrez, A., Sánchez, A., Beltrán-García, M., \& Mata, G. (2006). Bioconversion of agrowastes by Lentinula edodes: the high potential of viticulture residues. Applied Microbiology and Biotechnology, 71(4), 432-439. https://doi:10.1007/s00253-005-0241-1

Gil-Muñoz, R., Gómez-Plaza, E., Martínez, A., \& López-Roca, J. M. (1999) Evolution of Phenolic Compounds during Wine Fermentation and Postfermentation: Influence of Grape Temperature. Journal of Food Composition and Analysis, 12(4), 259-272. https://doi:10.1006/ifca.1999.0834

Habeeb AFSA, (1972). Reaction of protein sulfhydryl groups with Ellman's reagent. Methods Enzymol, 25: $\quad 457-464$. https://doi.org/10.1016/S0076 6879(72)25041-8

Kahyaoğlu M, Konar V, (2006). Biosurfactant Rhamnolipit Production by Pseudomonas aeruginosa Using Waste of Sugar Industry. Science and Eng J of Firat Univ, 18: 493-498.

Kalli, E., Lappa, I., Bouchagier, P., Tarantilis, P. A., \& Skotti, E. (2018). Novel application and industrial exploitation of winery by-products. Bioresources and Bioprocessing, 5(1). https://doi:10.1186/s40643-018-0232-6

Keser, S., Celik, S., \& Turkoglu, S. (2012). Total phenolic contents and freeradical scavenging activities of grape (Vitis viniferaL.) and grape products. International Journal of Food Sciences and Nutrition, 64(2), 210-216. https://doi:10.3109/09637486.2012.728199

Kilinc, E., \& Kalkan, H. (2003). High-performance Liquid Chromatographic Determination of Some Phenolic Acids of Turkish Commercial Wines: An Electrochemical Approach. Journal of Wine Research, 14(1), 17-23. https://doi:10.1080/0957126032000114982

Larrauri JA, Ruperez P, Calixto FS, (1996). Antioxidant activity of wine pomace. Am J Enol Vitic. 47: 369-372

Lee, I.-H., Hung, Y.-H., \& Chou, C.-C. (2008). Solid-state fermentation with fungi to enhance the antioxidative activity, total phenolic and anthocyanin contents of black bean. International Journal of Food Microbiology, 121(2), 150156. https://doi:10.1016/i.ijfoodmicro.2007.09.008

Liu, C., Sun, Z.-T., Du, J.-H., \& Wang, J. (2008). Response surface optimization of fermentation conditions for producing xylanase by Aspergillus niger SL-05. Journal of Industrial Microbiology \& Biotechnology, 35(7), 703-711. https://doi:10.1007/s10295-008-0330-0

Manconi, M., Marongiu, F., Manca, M. L., Caddeo, C., Sarais, G., Cencetti, C. Fadda, A. M. (2017). Nanoincorporation of bioactive compounds from red grape pomaces: In vitro and ex vivo evaluation of antioxidant activity. Internationa Journal of Pharmaceutics, 523(1), 159-166 https://doi:10.1016/j.ijpharm.2017.03.037

Marques De Souza CG, Zilly A, Peralta RM, (2002). Production of laccase as the sole phenoloxidase by a Brazilian strain of Pleurotus pulmonarius in solid state fermentation. J Basic Microbiol, 42: 83-90.

Martínez-Ávila, G. C., Aguilera-Carbó, A. F., Rodríguez-Herrera, R., \& Aguilar, C. N. (2011). Fungal enhancement of the antioxidant properties of grape waste Annals of Microbiology, 62(3), 923-930. https://doi:10.1007/s13213-011-0329-z Martins, I. M., Roberto, B. S., Blumberg, J. B., Chen, C.-Y. O., \& Macedo, G. A (2016). Enzymatic biotransformation of polyphenolics increases antioxidant activity of red and white grape pomace. Food Research International, 89, 533539. https://doi:10.1016/j.foodres.2016.09.009

Mertens D, (2005). AOAC official method 975.03. Metal in Plants and Pet Foods. Official Methods of Analysis, 18th edn. Horwitz W, GW Latimer, (Eds),pp. 3-4

Öztürk, S., Canbay, E., Kalkan Yıldırım, H., \& Sözmen, E., (2016). Phenolic Content and Potential Ant1-inflammatory Effects of Myrtus communis L. Products. FEBS Journal, vol.283, 74. https://doi: 10.1111/febs.13807

Pintać, D., Majkić, T., Torović, L., Orčić, D., Beara, I., Simin, N., . Lesjak, M. (2018). Solvent selection for efficient extraction of bioactive compounds from grape pomace. Industrial Crops and Products, 111, 379-390. https://doi:10.1016/j.indcrop.2017.10.038

Randhir, R., \& Shetty, K. (2007). Mung beans processed by solid-state bioconversion improves phenolic content and functionality relevant for diabetes and ulcer management. Innovative Food Science \& Emerging Technologies, 8(2), 197-204. https://doi:10.1016/j.ifset.2006.10.003

Re, R., Pellegrini, N., Proteggente, A., Pannala, A., Yang, M., \& Rice-Evans, C (1999). Antioxidant activity applying an improved ABTS radical cation 
decolorization assay. Free Radical Biology and Medicine, 26(9-10), 1231-1237. https://doi:10.1016/s0891-5849(98)00315-3

Sánchez, C. (2009). Lignocellulosic residues: Biodegradation and bioconversion by fungi. Biotechnology Advances, 27(2), 185-194 https://doi:10.1016/j.biotechadv.2008.11.001

Schieber, A., Stintzing, F. ., \& Carle, R. (2001). By-products of plant food processing as a source of functional compounds - recent developments. Trends in Food Science \& Technology, 12(11), 401-413. https://doi:10.1016/s09242244(02)00012-2

Sezer, E. D., Akçay, Y. D., İlanbey, B., Yıldırım, H. K., \& Sözmen, E. Y. (2007) Pomegranate Wine Has Greater Protection Capacity Than Red Wine on LowDensity Lipoprotein Oxidation. Journal of Medicinal Food, 10(2), 371-374 https://doi:10.1089/jmf.2006.210

Shah, M. P., Reddy, G. V., Banerjee, R., Ravindra Babu, P., \& Kothari, I. L. (2005). Microbial degradation of banana waste under solid state bioprocessing using two lignocellulolytic fungi (Phylosticta spp. MPS-001 and Aspergillus spp. MPS-002). Process Biochemistry, 40(1), 445-451. https://doi:10.1016/j.procbio.2004.01.020

Singleton VL, Rossi JA, (1965). Colorimetry of total phenolics with phosphomolybdic-phosphotungstic acid reagents. Am J Enol Vitic, 16: 144-158.

Teissedre PL, Frankel EN, Waterhouse AL, Peleg H, German JB, (1996) Inhibition of in vitro human LDL oxidation by phenolic antioxidants from grapes and wines. J Sci Food Agric, 70: 55-61. https://doi.org/10.1002/(SICI)10970010(199601)70:1<55::AID-JSFA471>3.0.CO;2-X

Teleszko, M., \& Wojdyło, A. (2015). Comparison of phenolic compounds and antioxidant potential between selected edible fruits and their leaves. Journal of Functional Foods, 14, 736-746. https://doi:10.1016/i.jff.2015.02.041

Topakas, E., Stamatis, H., Biely, P., Kekos, D., Macris, B. ., \& Christakopoulos, P. (2003). Purification and characterization of a feruloyl esterase from Fusarium oxysporum catalyzing esterification of phenolic acids in ternary water-organic solvent mixtures. Journal of Biotechnology, 102(1), 33-44. https://doi:10.1016/s0168-1656(02)00363-2

Vattem, D. A., \& Shetty, K. (2002). Solid-State Production of Phenolic Antioxidants From Cranberry Pomace By Rhizopus Oligosporus. Food Biotechnology, 16(3), 189-210. https://doi:10.1081/fbt-120016667

Vattem, D. A., \& Shetty, K. (2003). Ellagic acid production and phenolic antioxidant activity in cranberry pomace (Vaccinium macrocarpon) mediated by Lentinus edodes using a solid-state system. Process Biochemistry, 39(3), $367-$ 379. https://doi:10.1016/s0032-9592(03)00089-x

Yıldırım, H. K., Akçay, Y. D., Güvenc, U., \& Sözmen, E. Y. (2004). Protection capacity against low-density lipoprotein oxidation and antioxidant potential of some organic and non-organic wines. International Journal of Food Sciences and Nutrition, 55(5), 351-362. https://doi:10.1080/09637480412331319781

Yıldırım, H. K., Akcay, Y. D., Guvenc, U., Altindisli, A., \& Sozmen, E. Y. (2005). Antioxidant activities of organic grape, pomace, juice, must, wine and their correlation with phenolic content. International Journal of Food Science and Technology, 40(2), 133-142. https://doi:10.1111/j.1365-2621.2004.00921.x

Yıldırım, H. K., İşçi, B., \& Altındişli, A. (2015). Chemometric and phenolic attributes of blended wines assessed by multivariate techniques. Journal of the Institute of Brewing, 121(4), 636-641. https://doi:10.1002/jib.258

Zheng, Z., \& Shetty, K. (1998). Cranberry processing waste for solid state fungal inoculant production. Process Biochemistry, 33(3), 323-329. https://doi:10.1016/s0032-9592(97)87514-0

Zheng, Z., \& Shetty, K. (2000), a. Solid state production of polygalacturonase by Lentinus edodes using fruit processing wastes. Process Biochemistry, 35(8), 825830. https://doi:10.1016/s0032-9592(99)00143-0

Zheng, Z., \& Shetty, K. (2000), b. Solid-State Bioconversion of Phenolics from Cranberry Pomace and Role ofLentinus edodes $\beta$-Glucosidase. Journal of Agricultural and Food Chemistry, 48(3), 895-900. https://doi:10.1021/jf990972u 